\title{
A PRODUÇÃO ACADÊMICA SOBRE A FABRICAÇÃO DIGITAL NAS ESCOLAS BRASILEIRAS DE ARQUITETURA E URBANISMO
}

\section{THE SCIENTIFIC PRODUCTION ON DIGITAL MANUFACTURING IN BRAZILIAN SCHOOLS OF ARCHITECTURE AND URBANISM}

\author{
Iago Longue Martins ${ }^{1}$ \\ Instituto Federal de Educação, Ciência e Tecnologia Fluminense, Campos dos Goytacazes, RJ, Brasil, \\ iagolongue.arqurb@gmail.com
}

Zander Ribeiro Pereira Filho ${ }^{2}$

Instituto Federal de Educação, Ciência e Tecnologia Fluminense, Campos dos Goytacazes, RJ, Brasil, zander.filho@iff.edu.br

\begin{abstract}
Resumo
A fabricação digital tem atuado de maneira bastante transformadora na arquitetura, alterando a forma como os projetos são concebidos e construídos. A técnica reduz a possibilidade de erros de execução, já que o arquiteto adquire maior controle sobre o processo, seja pela materialização digital ou física da ideia. Desse modo, o presente artigo tem por objetivo avaliar o cenário atual de discussão da fabricação digital nas escolas de arquitetura e urbanismo no Brasil, através da análise da produção bibliográfica dessas instituições. De forma específica, pretende-se conhecer como esse cenário tem evoluído desde a publicação do primeiro estudo sobre o tópico no país, desenvolvido por Regiane Trevisan Pupo no ano de 2008, além de catalogar, seguindo uma lógica temporal, as áreas de abordagem de cada trabalho. Os artigos analisados mostram que houve uma popularização do assunto no âmbito acadêmico, com a multiplicação dos laboratórios de prototipagem rápida e das linhas de pesquisa abordando o tema, o que indica que a fabricação digital tem se consolidado como área de interesse na arquitetura, mesmo com algumas resistências, como a escassez de mão de obra fluente na aplicação da técnica, além do número limitado de professores que trabalham com essas tecnologias nas instituições de ensino.
\end{abstract}

Palavras-chave: Fabricação digital. Prototipagem rápida. Arquitetura. Brasil.

\begin{abstract}
Digital manufacturing has been very transformative in architecture, changing the way buildings are designed and built. The technique reduces the possibility of execution errors, since the architect acquires greater control over the process, either by the digital or physical materialization of the idea. Thus, the present article aims to evaluate the current scenario of discussion of digital manufacturing in Brazilian schools of architecture and urbanism, through the analysis of the bibliographic production of these institutions. Specifically, this study intends to reveal how this scenario has evolved since the first study on the topic in the country, developed by Regiane Trevisan Pupo in the year of 2008. It is also intended to catalog, following a temporal logic, the areas of the approach of each work. The analysis shows that there has been a popularization of the subject in the academic scope, with the multiplication of fast prototyping laboratories and lines of research addressing the theme. Digital manufacturing has become a consolidated area of interest in architecture, even with some barries, such as the shortage of skilled labor in the application of the technique, in addition to the limited number of teachers working with these technologies in educational institutions.
\end{abstract}

Keywords: Digital fabrication. Rapid prototyping. Architecture. Brazil.

How to cite this article:

MARTINS, Iago Longue; PEREIRA FILHO, Zander Ribeiro. A produção acadêmica sobre a fabricação digital nas escolas brasileiras de arquitetura e urbanismo. PARC Pesquisa em Arquitetura e Construção, Campinas, SP, v. 10, p. e019007, fev. 2019. ISSN 1980-6809. Disponível em: <https://periodicos.sbu.unicamp.br/ojs/index.php/parc/article/view/8652734>. Acesso em: 26 fev. 2019. doi:https://doi.org/10.20396/parc.v10i0.8652734. 


\section{Introdução}

De acordo com Kolarevic (2001), a Era da Informação, assim como a Era Industrial, que a precedeu, está transformando não apenas a maneira de se projetar os edifícios, mas também como estes são construídos. Os meios de produção digitalmente dirigidos, caracterizados por transformações imprevisíveis, porém consistentes, de estruturas tridimensionais, estão fazendo surgir novas possibilidades na arquitetura.

Gonçalves (2005) ressalta que a presença destes fenômenos na arquitetura contemporânea destaca claramente duas particularidades fundamentais no exercício de projeto: a integração da tecnologia na linguagem plástica da arquitetura e a inserção do conhecimento técnico-científico no saber-fazer do arquiteto, de forma que se torna evidente, segundo Laverde e Oliveira (2014), que a arquitetura está condicionada à evolução tecnológica.

Além disso, as tecnologias de fabricação digital podem ser inseridas de maneira integral ou parcial no passo a passo construtivo, visto que possuem a capacidade de atuar nas mais variadas etapas de execução de um projeto. Pupo (2008) afirma que tais técnicas podem ser utilizadas tanto na concepção da forma arquitetônica, quanto na construção do molde em poliestireno do elemento construtivo em cortadoras controladas por computador, como também na preparação do molde para aplicação de concreto, na aplicação da ferragem e concretagem, no acabamento, na desmoldagem, na confecção de elementos construtivos prontos para serem inseridos na obra, na localização de certas peças dentro de um projeto e na finalização da obra, como, por exemplo, na limpeza.

Entretanto, no Brasil a utilização da fabricação digital como técnica construtiva é algo ainda restrito, devido à pequena industrialização do país, que, conforme exposto por Borges (2016) não foi capaz de desenvolver um perfil majoritariamente tecnológico no setor da construção civil, como pode ser notado nos países com uma indústria madura. Sendo assim, a implementação de tais tecnologias fica a cargo dos centros de ensino superior, por meio da experimentação e formação de profissionais capacitados para trabalhar com a fabricação digital, de modo a gerar a industrialização da construção civil através da demanda dos próprios profissionais.

Desse modo, o presente artigo tem por objetivo geral avaliar a forma que as discussões a respeito da fabricação digital nas escolas de arquitetura e urbanismo no Brasil estão se desenvolvendo, através da análise da produção bibliográfica dessas academias. Essa estratégia consiste em uma amostragem da realidade do ensino, já que o processo de publicação de um artigo demanda certa dedicação por parte das instituições, o que faz com que nem todas demonstrem os trabalhos e pesquisas produzidos utilizando desta tipologia, restringindo, assim, a possibilidade de se obter um retrato fidedigno da situação em questão por meio deste método. De forma específica, pretende-se conhecer como esse cenário tem evoluído, de modo geral, desde a publicação do primeiro estudo sobre o estado da arte da fabricação digital no país, desenvolvido por Regiane Trevisan Pupo no ano de 2008, além de catalogar, seguindo uma lógica temporal, as áreas de abordagem de cada trabalho envolvendo tais tecnologias e a arquitetura.

\section{Método}

A metodologia utilizada para o desenvolvimento da pesquisa em questão foi a revisão sistemática de literatura, que, segundo Sampaio e Mancini (2007), é importante na integração de um conjunto de informações oriundas de estudos realizados 
independentemente sobre determinado assunto, auxiliando na orientação para investigações futuras.

Souza, Silva e Carvalho (2010) indicam que a revisão integrativa consiste em seis etapas a saber: elaboração da pergunta norteadora, busca ou amostragem na literatura nas bases de dados, coleta dos dados aderentes ao tema, análise crítica dos estudos incluídos, a discussão cruzada dos resultados e, finalmente, a apresentação do resultado obtido pelo estudo.

Logo, os estágios predefinidos para o desenvolvimento do presente artigo foram a definição do foco, com escolha das palavras-chave a serem inseridas na base de dados, seguida da sucessiva aplicação de filtros para eliminação dos resultados não pertinentes. Após essa etapa, cada trabalho coletado é analisado sob diferentes enfoques, objetivando a extração de informações congruentes com os propósitos delimitados para a pesquisa, para então serem traçadas as concordâncias e conflitos dos dados obtidos.

Definição do foco

Sob a ótica da fabricação digital na arquitetura, a temática da presente pesquisa se concentrou em investigar a evolução desta abordagem na arquitetura e urbanismo nas instituições de ensino superior brasileiras, a partir de uma análise da produção acadêmica no período de 2009 a 2018. Tal estudo se somará a uma análise comparativa do cenário descrito por Pupo (2008) em seu artigo "Ensino da Prototipagem Rápida e Fabricação Digital para Arquitetura e Construção no Brasil: Definições e Estado da Arte", que já esboçava um cenário geral da utilização das novas tecnologias na academia brasileira nos anos anteriores ao período investigado.

\section{Busca dos termos}

Após a definição do enfoque, foram escolhidas as palavras-chave para a busca do material bibliográfico. Visando abranger um amplo escopo sobre a temática no Brasil, as palavras selecionadas foram "fabricação", "digital", "arquitetura", "ensino" e "Brasil", além das palavras em inglês "fabrication" e "architecture", que foram lançadas nas bases de dados Scielo e Scopus e no mecanismo de busca do Google Acadêmico. O resultado dessa busca generalizada se configurou em um total de 268 documentos, conforme mostrado no Quadro 1.

Quadro 1 - Palavras-chave da pesquisa e detalhes da filtragem

\begin{tabular}{|c|c|c|}
\hline \multicolumn{2}{|r|}{ Bases de dados (Google Acadêmico, Scielo e Scopus) } & Documentos encontrados \\
\hline Palavras-chave & $\begin{array}{c}\text { "fabricação" e "digital" e "arquitetura" e "ensino" e "Brasil" e "fabrication" } \\
\text { e "architecture" }\end{array}$ & 268 \\
\hline \multirow{3}{*}{ Filtros } & $\begin{array}{c}\text { Limite temporal } \\
2009-2018 \\
\end{array}$ & 223 \\
\hline & Leitura de títulos & 97 \\
\hline & Leitura de resumos & 68 \\
\hline \multicolumn{2}{|r|}{ Total de documentos aderentes } & 68 \\
\hline
\end{tabular}

Fonte: Os autores.

Em seguida, foram utilizados filtros de forma a refinar os materiais disponíveis. $\mathrm{O}$ primeiro filtro aplicado foi o limite temporal definido pelo intervalo entre os anos de 2009 e 2018, que resultou em 223 documentos. Ou seja, no período selecionado, produziu-se quase cinco vezes mais conteúdo a respeito da temática selecionada que nos anos anteriores a 2009, ressaltando um aumento da popularidade do assunto em questão. 
O filtro seguinte consistiu na leitura de títulos, visando identificar quais materiais melhor se enquadravam nos objetivos da presente pesquisa, ou seja, quais explicitavam que a fabricação digital era o foco principal dos estudos desenvolvidos. A seleção resultou em 97 títulos, que tiveram, posteriormente, seus respectivos resumos analisados com o intuito de avaliar de forma mais apurada o conteúdo exposto pelos autores, para assim selecionar os textos mais pertinentes. $O$ grupo resultante de bibliografias consistiu em um total de 68 trabalhos.

\section{Resultados e Discussão}

\section{Métricas preliminares}

A fim de analisar qualitativamente os documentos selecionados, estes foram reorganizados em diferentes grupos. Para a primeira análise, foi feita uma distribuição da produção ao longo do período estipulado para a pesquisa, ou seja, entre os anos de 2009 e 2018. Além disso, os trabalhos foram discriminados em dois perfis: (i) teórico, se o material se tratava de uma discussão teórica da questão da fabricação digital na arquitetura; (ii) prático, se o objetivo central era a documentação de algum experimento autoral envolvendo o tema escolhido.

O resultado dessa seleção é explicitado na Figura 1. Tal procedimento foi importante para avaliar a contribuição brasileira para a produção de conhecimento sobre a utilização das tecnologias de fabricação digital na arquitetura. Ademais, uma maior produção de experimentos envolvendo a temática demonstra um interesse pela pesquisa aplicada, além da disponibilidade aos maquinários necessários às atividades experimentais de fabricação.

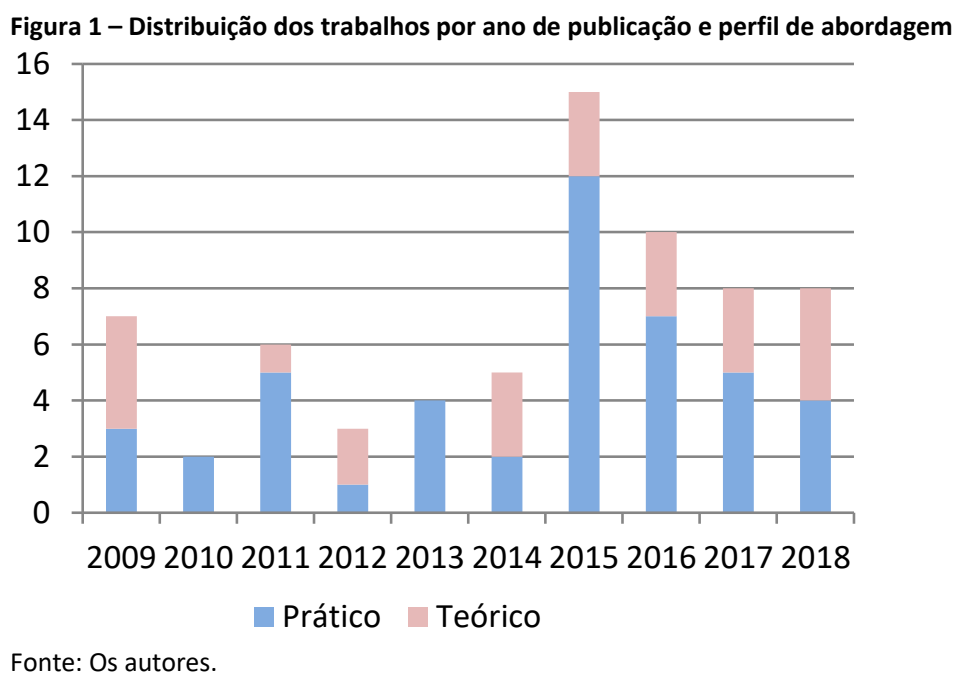

Conforme visto na Figura 1, houve um pico de publicação dos estudos sobre a fabricação digital em 2015, ano em que a pesquisa encontrou o maior registro de publicações no Brasil, seguido de sucessivas quedas nos anos de 2016 e 2017, e de uma estabilização no ano de 2018, porém mantendo-se acima da média de publicações dos anos anteriores a 2015. As razões por trás do aumento na produção bibliográfica nesse período específico são exploradas mais adiante.

Posteriormente, buscou-se mapear a origem do material bibliográfico, com o intuito de analisar quais instituições e estados da federação estão mais atuantes na pesquisa sobre a fabricação digital no contexto arquitetônico. A divisão entre os perfis teórico e prático dos artigos foi mantida para a análise das instituições, com a intenção de inferir por meio 
do tipo de produção a disponibilidade de laboratórios de prototipagem rápida no local, pois a ausência de pesquisas de cunho experimental pode ser um indício de dificuldade de acesso às tecnologias de fabricação digital, seja pela carência de um laboratório de prototipagem rápida na própria instituição, seja pela indisponibilidade de tais recursos na região. Os resultados dessa exploração estão demonstrados na Figura 2 e na Figura 3.

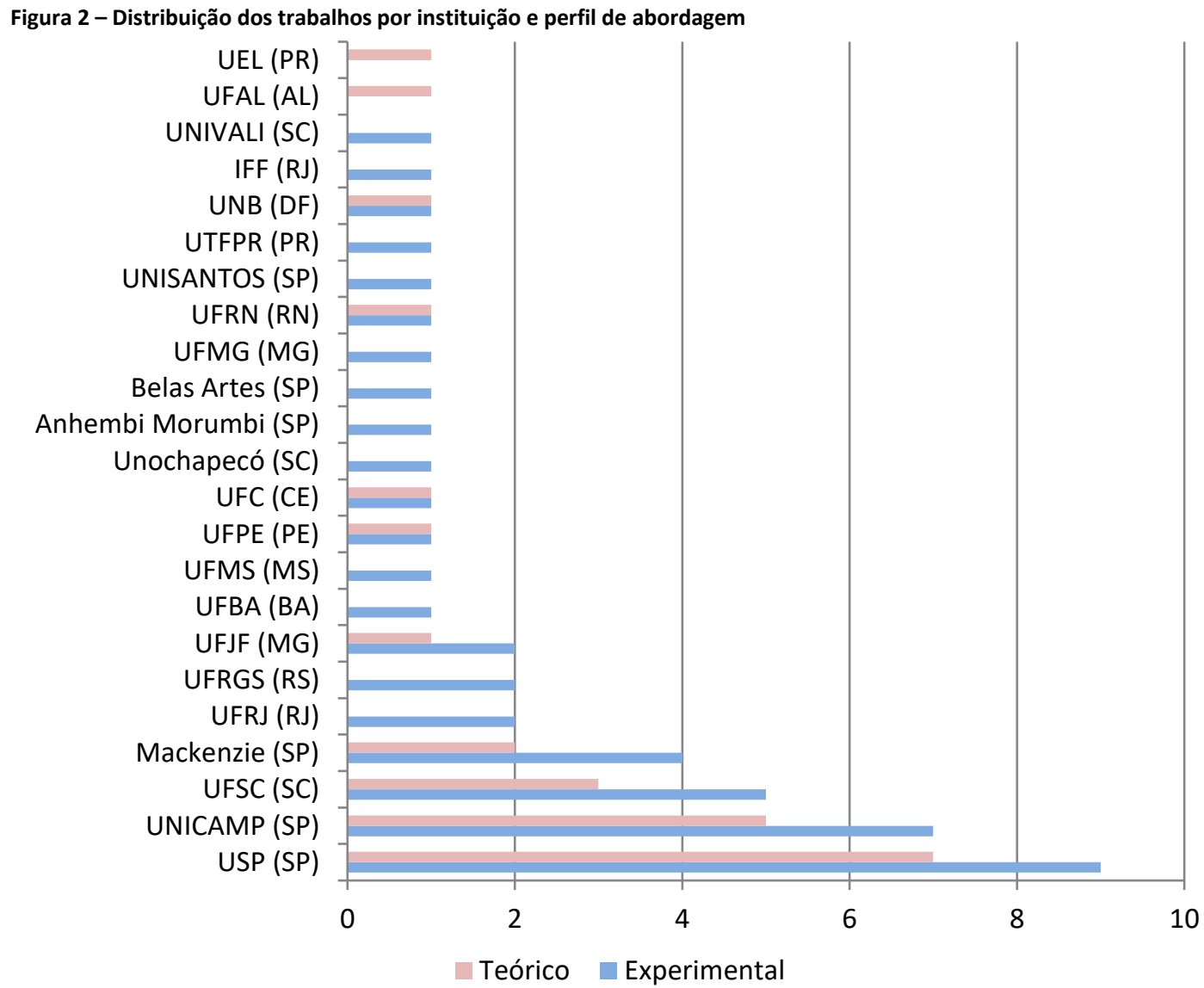

Fonte: Os autores.

Figura 3 - Participação dos Estados no total da produção bibliográfica sobre a temática no período selecionado

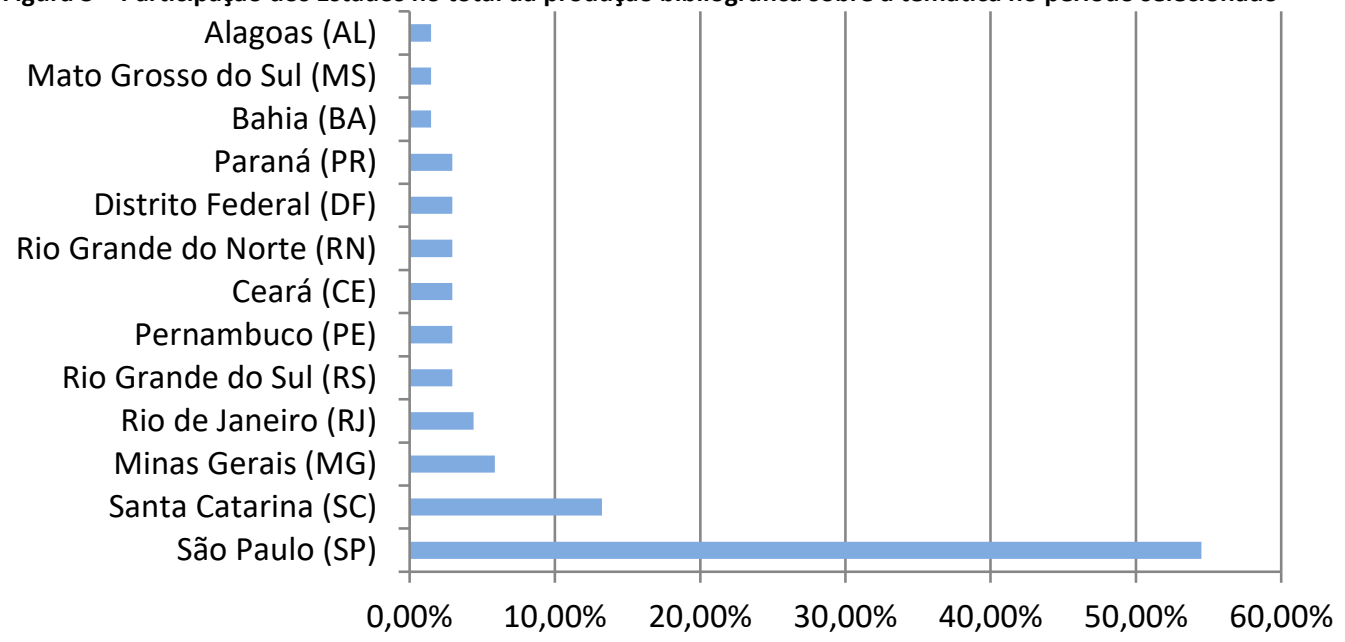

Fonte: Os autores.

Analisando este resultado, observa-se que há uma concentração das pesquisas a respeito da fabricação digital em certas instituições, principalmente nos estados de São 
Paulo e Santa Catarina. As instituições de ensino paulistas concentram 54\% de toda a produção bibliográfica encontrada para o período, o que demonstra um amplo interesse dessa região em estudar e testar tais técnicas dentro do meio arquitetônico e da construção civil.

O restante dos trabalhos é proveniente de outras 17 instituições distribuídas pelo território nacional e não produzindo mais que dois títulos para o momento e enfoque selecionados, com exceção da Universidade Federal de Santa Catarina (UFSC), que contribuiu com sete publicações entre os anos de 2009 e 2018, além da Universidade Federal de Juiz de Fora (UFJF), que contribuiu com três trabalhos. O fato demonstra o começo de uma popularização do assunto no meio acadêmico nacional, principalmente devido à participação de variadas entidades nas diferentes regiões do país.

A etapa seguinte da análise se ocupou em mensurar o grau de participação das instituições acadêmicas paulistas, em comparação com o restante do país, no aumento da publicação sobre o tema no ano de 2015, já que estas lideram o acumulado da produção bibliográfica selecionada para o período explorado. Os resultados, visualizados na Figura 4, mostram que no momento anterior a 2015, o estado de São Paulo estava à frente na cota de publicações a respeito da fabricação digital na arquitetura, com exceção do ano de 2013. Entretanto, nos anos de 2015 a 2018 houve um aumento da participação dos demais estados, superando até mesmo a porcentagem paulista na produção bibliográfica dos anos de 2015 e 2017, o que evidencia a questão da popularização da temática no restante do país.

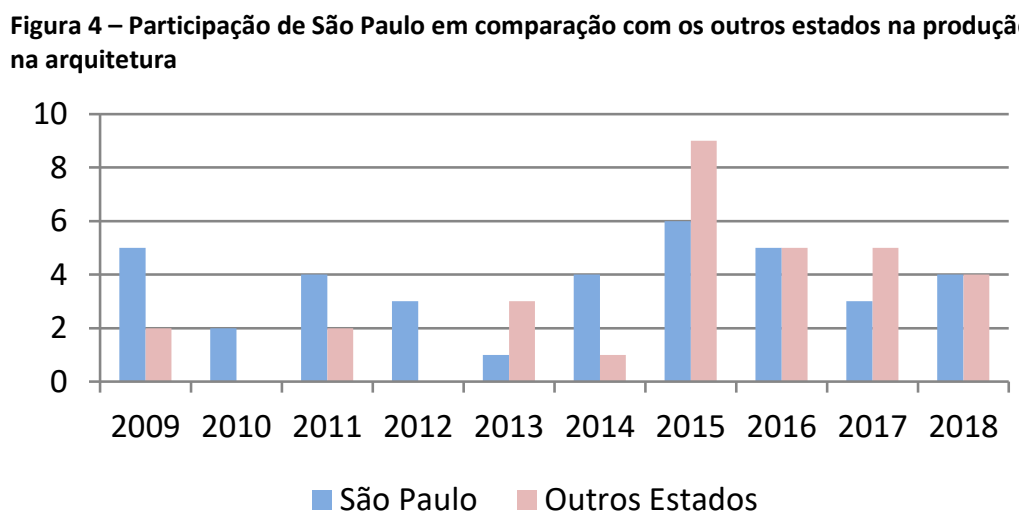

Fonte: Os autores.

Tal fato explicita o pioneirismo das instituições acadêmicas paulistas, atuando como polos implementadores de discussão das novas tecnologias aplicadas à arquitetura e à construção civil, já que foram as primeiras no país a discutir e experimentar com propriedade a fabricação digital sob enfoque arquitetônico. Além disso, o estado de São Paulo se mantém em posição de destaque, com uma quantidade de publicações expressivas, se comparado aos demais estados da federação, o que demonstra o interesse da região pela fabricação digital na arquitetura.

Em seguida, buscou-se qualificar a produção bibliográfica selecionada, para, então, ser possível avaliar qual tipologia textual teve maior impacto no pico de publicações ocorrido no ano de 2015. Para isso, os trabalhos foram divididos em cinco diferentes perfis: trabalho final de graduação, dissertação de mestrado, tese de doutorado, artigos publicados em periódicos e artigos publicados em anais de eventos. O resultado da análise está exposto na Figura 5. 


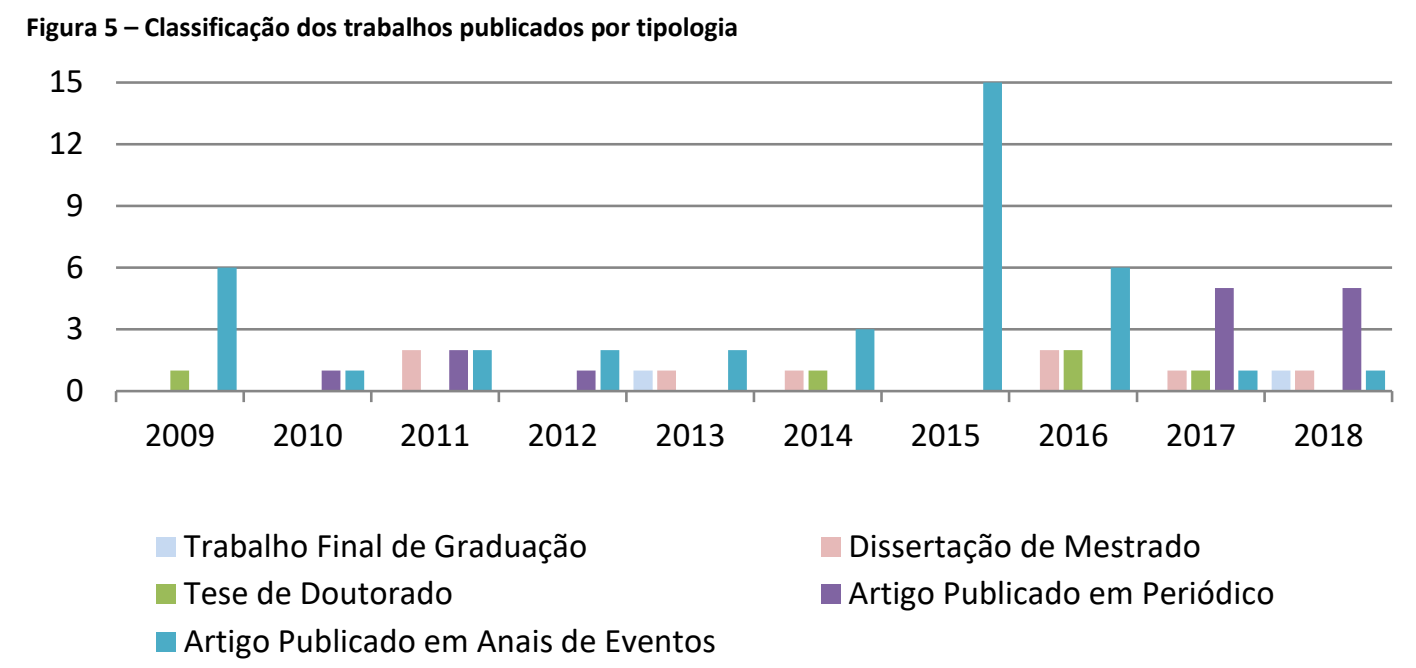

Fonte: Os autores.

Conforme mostrado pela Figura 5, a tipologia responsável pelo pico de publicações a respeito da fabricação digital na arquitetura no ano de 2015 foi "artigo publicado em anais de eventos". A pesquisa mostrou que 13 dos 15 artigos selecionados naquele ano foram publicados pelo XIX Congresso da Sociedade Iberoamericana de Gráfica Digital (SiGraDi 2015), ocorrido em Florianópolis. Os demais artigos foram publicados cada um por outros dois eventos: o VII Seminário Projetar 2015, sediado pela Universidade Federal do Rio Grande do Norte, em Natal, e o VII Encontro de Tecnologia de Informação e Comunicação na Construção, que aconteceu em Recife.

Apesar de o SiGraDi ter ocorrido no Brasil em duas situações anteriores a 2015 (em 2009, na cidade de São Paulo, e em 2012, na cidade de Fortaleza), foi apenas em 2015 que houve um engajamento maior de unidades acadêmicas situadas em diferentes regiões do Brasil, culminando no pico de publicações identificado pela presente pesquisa. Este indício corrobora a ideia de propagação das discussões no meio acadêmico envolvendo a fabricação digital na arquitetura, iniciadas pelas instituições acadêmicas paulistas.

Após o ano de 2015, observa-se uma alteração no perfil de publicações a respeito da temática. No ano de 2016, a tipologia mais encontrada ainda foi "artigo publicado em anais de eventos", em que todos esses artigos foram publicados pelo SiGraDi 2016, ocorrido em Buenos Aires. Entretanto, nos anos de 2017 e 2018, houve uma preferência por publicações sobre a fabricação digital na arquitetura em periódicos, especificamente os de circulação em meio eletrônico, em um nível que não havia sido detectado anteriormente. Outra característica marcante a esse respeito é a diversidade de periódicos nos quais esses artigos foram publicados, totalizando nove revistas para um acumulado de dez artigos publicados nos anos de 2017 e 2018, o que não possibilita a identificação de um título especializado na temática abordada.

Por fim, foi feita uma seleção de universidades que, no período da publicação dos trabalhos analisados, apresentavam indícios de possuírem ferramentas para prototipagem rápida. Este diagnóstico foi elaborado a partir da análise do roteiro dos experimentos documentados pelos trabalhos, os quais indicavam se os mesmos foram desenvolvidos na própria instituição de ensino ou com o apoio de uma empresa que desenvolve serviços de fabricação digital. A Universidade Estadual de Londrina (UEL) e a Universidade Federal do Alagoas (UFAL) foram excluídas de tal análise, devido à ausência de registros experimentais nos artigos publicados por essas instituições, restando, assim, um grupo com 21 unidades acadêmicas. O resultado obtido na investigação está registrado no Quadro 2. 
MARTINS, Iago Longue; PEREIRA FILHO, Zander Ribeiro.

A produção acadêmica sobre a fabricação digital nas escolas brasileiras de arquitetura e urbanismo

\begin{tabular}{|c|c|c|}
\hline Instituição & $\begin{array}{l}\text { Indícios de disponibilidade de ferramentas } \\
\text { para prototipagem rápida na Instituição }\end{array}$ & $\begin{array}{c}\text { Ano de publicação do } \\
\text { artigo mais recente } \\
\text { selecionado }\end{array}$ \\
\hline Universidade Federal de Minas Gerais (UFMG) - MG & Sim & 2011 \\
\hline Universidade Federal do Ceará (UFC) - CE & Sim & 2014 \\
\hline $\begin{array}{l}\text { Universidade Federal de Mato Grosso do Sul (UFMS) } \\
- \text {-MS }\end{array}$ & Sim & 2015 \\
\hline Universidade Federal do Rio de Janeiro (UFRJ) -RJ & Sim & 2015 \\
\hline $\begin{array}{l}\text { Centro Universitário Belas Artes de São Paulo (Belas } \\
\text { Artes) - SP }\end{array}$ & Sim & 2015 \\
\hline Universidade Federal de Pernambuco (UFPE) - PE & $\operatorname{Sim}$ & 2017 \\
\hline $\begin{array}{l}\text { Universidade Federal do Rio Grande do Norte } \\
\text { (UFRN) - RN }\end{array}$ & Sim & 2017 \\
\hline Universidade Católica de Santos (UNISANTOS) - SP & Sim & 2017 \\
\hline Universidade de Brasília (UNB) - DF & Sim & 2017 \\
\hline $\begin{array}{l}\text { Universidade Federal do Rio Grande do Sul (UFRGS) } \\
\text {-RS }\end{array}$ & Sim & 2017 \\
\hline Universidade Estadual de Campinas (UNICAMP) - SP & Sim & 2017 \\
\hline Universidade de São Paulo (USP) - SP & Sim & 2018 \\
\hline $\begin{array}{l}\text { Universidade Presbiteriana Mackenzie (Mackenzie) - } \\
\text { SP }\end{array}$ & Sim & 2018 \\
\hline Universidade Federal de Santa Catarina (UFSC) -SC & $\operatorname{Sim}$ & 2018 \\
\hline Universidade Federal de Juiz de Fora (UFJF) - MG & Sim & 2018 \\
\hline Universidade Federal da Bahia (UFBA) - BA & Não & 2009 \\
\hline Universidade Anhembi Morumbi (Anhembi) - SP & Não & 2013 \\
\hline $\begin{array}{c}\text { Universidade Tecnológica Federal do Paraná } \\
\text { (UTFPR) - PR }\end{array}$ & Não & 2013 \\
\hline $\begin{array}{l}\text { Universidade Comunitária da Região de Chapecó } \\
\text { (Unochapecó) -SC }\end{array}$ & Não & 2015 \\
\hline $\begin{array}{c}\text { Instituto Federal de Educação, Ciência e Tecnologia } \\
\text { Fluminense (IFF) - RJ }\end{array}$ & Não & 2018 \\
\hline Universidade do Vale do Itajaí (UNIVALI) - SC & Não & 2018 \\
\hline
\end{tabular}

Fonte: Os autores.

De acordo com o Quadro 2, a maioria das instituições que publicaram um trabalho referente a experimentações envolvendo a fabricação digital na arquitetura apresentaram indícios de possuírem algum maquinário de prototipagem rápida na própria unidade acadêmica. As demais instituições de ensino que não apresentaram esses indícios realizaram as pesquisas em parceria com algum laboratório privado ou pertencente a algum outro centro educacional, como foi o caso da Universidade Federal da Bahia (UFBA), da Universidade Anhembi Morumbi (Anhembi), do Instituto Federal de Educação, Ciência e Tecnologia Fluminense (IFF) e da Universidade do Vale do Itajaí (UNIVALI). Outras, como a Universidade Tecnológica Federal do Paraná (UTFPR) e a Universidade de Brasília (UNB), não realizaram atividades de materialização de seus experimentos para os trabalhos selecionados, finalizando-os na fase de concepção digital, não necessitando, pois, de um laboratório para essas atividades. Entretanto, vale ressaltar que a falta de concretização de protótipos não indica a ausência de disponibilidade de ferramentas para fabricação digital na unidade.

Análise dos textos - Escopo de discussão

A definição dos eixos de discussão de cada artigo se deu através da leitura de resumos e da seleção das palavras-chaves utilizadas, de modo a suprir um dos objetivos da presente pesquisa, que se trata da catalogação das aplicações das novas tecnologias no contexto arquitetônico, bem como das discussões em torno da temática, seguindo uma linha temporal. 
Para complementar tal observação, foi feita uma pesquisa no Diretório de Grupos de Pesquisas do CNPq, assim como feito por Pupo (2008), com o intuito de localizar as linhas pesquisas registradas nessa base de dados. Foram utilizadas as palavras-chave "fabricação", "digital" e "arquitetura" para a busca. Como resultado, foram encontradas cinco linhas de pesquisa, que estão registradas no Quadro 3, porém apenas três linhas coincidem com os artigos encontrados, já que não foram localizados trabalhos provenientes da Universidade Federal de Santa Maria (UFSM).

Quadro 3 - Linhas de pesquisas encontradas
\begin{tabular}{|c|c|c|}
\hline Linha de Pesquisa & $\begin{array}{c}\text { Grupo de Pesquisa } \\
\text { Ensino de Projeto de Arquitetura }\end{array}$ & $\begin{array}{c}\text { Tecnologias digitais de fabricação aplicadas à } \\
\text { produção do Design e Arquitetura } \\
\text { Contemporâneos (DIGI FAB) }\end{array}$ \\
\hline Fabricação Digital & $\begin{array}{c}\text { Laboratório de Modelagem em Arquitetura } \\
\text { (ModeLAB) }\end{array}$ & Instituição \\
\hline $\begin{array}{c}\text { UNB } \\
\text { Arquitetura e Urbanismo }\end{array}$ & $\begin{array}{c}\text { Laboratório de Modelagem em Arquitetura } \\
\text { (ModeLAB) }\end{array}$ & UFSM \\
\hline $\begin{array}{c}\text { Modelagem Paramétrica/Algorítmica e } \\
\text { Fabricação Digital para Arquitetura e Urbanismo }\end{array}$ & UFSM \\
\hline $\begin{array}{c}\text { Modelagem Paramétrica e Fabricação de } \\
\text { Componentes não Padronizados em Arquitetura }\end{array}$ & Arquitetura, Processo de Projeto e Análise Digital & Mackenzie \\
\hline
\end{tabular}

Por conseguinte, foram estabelecidos 17 eixos de discussão: "fabricação digital”, "modelagem paramétrica”, "modelagem digital”, "prototipagem rápida”, "tecnologia e ensino de projeto", "fabricação digital e prática profissional", "interface da modelagem digital em BIM com prototipagem rápida", "fabricação digital e habitação popular", "modelagem paramétrica e habitação popular", "fabricação digital e detalhamento", "fabricação digital e inclusão", "fabricação digital e intervenção em estruturas pré-existentes", "fabricação digital e arquitetura efêmera", "análise digital da arquitetura moderna", "complexidade e pensamento paramétrico", "modelagem, digitalização 3D e prototipagem rápida" e "fabricação digital e o movimento maker". Tais eixos foram utilizados para classificar os artigos na análise a seguir.

Entretanto, antes de iniciar a discussão das análises, é válido exprimir os significados de alguns termos supracitados, a fim de elucidar a interpretação adotada. Por exemplo, a fabricação digital é um processo em que uma máquina, controlada por um computador, é usada para gerar um produto a partir de projetos digitais. A prototipagem rápida, por sua vez, está contida na fabricação digital (SASS; OXMAN, 2006), já que, por meio desta, protótipos físicos em escala, voltados para a experimentação e aprendizagem, testes e provas, comunicação e interação, podem ser fabricados a partir dos mesmos projetos digitais (CHUA; LEONG; LIM, 2010). Isto posto, o termo "prototipagem rápida" foi utilizado pelo presente artigo para designar meios de fabricação digital para produção de objetos experimentais em escala.

Da mesma forma, a modelagem digital e a modelagem paramétrica se diferenciam. A modelagem digital é definida por processos de criação e transformação de formas em meio computacional (KOLAREVIC, 2003), em que o computador atua como ferramenta principal do processo criativo (CANNAERTS, 2009). Nesse sentido, a modelagem paramétrica pode ser entendida como uma das modalidades de modelagem digital, na qual o método de criação e transformação de formas não ocorre por meio da atuação direta sobre o objeto modelado, mas, sim, sobre os parâmetros e relações que dão forma a este objeto (KOLAREVIC,2003). 
Assim, conforme exposto pelo Quadro 4, no ano de 2009, os trabalhos publicados se concentravam em explorar a aplicação das tecnologias de fabricação digital no ensino de projeto de arquitetura, bem como de seus impactos no meio profissional, através de análises de projetos já construídos utilizando a técnica. Este cenário denota uma preocupação em compreender a fabricação digital, para depois aplicá-la no contexto acadêmico.

Quadro 4 - Temáticas abordadas no ano de 2009

\begin{tabular}{|c|c|c|}
\hline Eixo de discussão & Quantidade & $\begin{array}{c}\text { Autores } \\
\text { Pupo e Celani (2009) }\end{array}$ \\
\hline Fabricação digital & 02 & $\begin{array}{c}\text { Bruscato, Alvarado e Montoya (2009); } \\
\text { Silva et al. (2009) }\end{array}$ \\
\hline Fabricação digital e prática profissional & 02 & Oliveira e Fabrício (2009); Pupo (2009) \\
\hline Tecnologia e ensino de projeto & 02 & Florio (2009) \\
\hline Modelagem paramétrica & 01 &
\end{tabular}

No ano de 2010, vê-se que as atividades experimentais envolvendo as ferramentas de produção digital começaram a ser desenvolvidas, ainda que em número pequeno, demonstrando um amadurecimento das pesquisas a respeito do tema (Quadro 5).

Quadro 5 - Temáticas abordadas no ano de 2010

\begin{tabular}{|c|c|c|}
\hline Eixo de discussão & Quantidade & Autores \\
\hline $\begin{array}{c}\text { Modelagem, digitalização 3D e } \\
\text { prototipagem rápida }\end{array}$ & 02 & $\begin{array}{c}\text { Celani e Piccoli (2010); } \\
\text { Lara et al. (2010) }\end{array}$ \\
\hline
\end{tabular}

Fonte: Os autores.

De acordo com o Quadro 6, no ano de 2011 houve uma multiplicação dos eixos de discussão dos trabalhos publicados, inaugurando a aplicação das novas tecnologias no processo de construção de habitações populares, estimulados, em grande parte, pelo experimento desenvolvido por Botha e Sass (2006), intitulado The Instant House.

Quadro 6 - Temáticas abordadas no ano de 2011

\begin{tabular}{|c|c|c|}
\hline Eixo de discussão & Quantidade & Autores \\
\hline Tecnologia e ensino de projeto & 02 & Florio (2011); \\
Oliveira (2011)
\end{tabular}

Fonte: Os autores.

Segundo o Quadro 7, no ano de 2012 houve uma redução na diversidade de eixos temáticos explorados, bem como nas publicações, porém a tendência de se explorar diferentes contextos envolvendo as novas tecnologias se manteve, revelando que o processo de assimilação da inovação por parte das instituições ainda estava em curso.

Quadro 7 - Temáticas abordadas no ano de 2012

\begin{tabular}{|c|c|c|}
\hline Eixo de discussão & Quantidade & Autores \\
\hline Fabricação digital & 01 & Barbosa Neto, Araújo e Celani (2012) \\
\hline Modelagem paramétrica & 01 & Florio (2012) \\
\hline Tecnologia e ensino de projeto & 01 & Celani (2012) \\
\hline
\end{tabular}

Fonte: Os autores.

Já no ano de 2013, de acordo com o Quadro 8, percebe-se que o escopo de pesquisa relacionada à fabricação digital começa a se expandir, passando a abranger especialidades como arquitetura efêmera, entretanto as pesquisas sobre as tecnologias 
MARTINS, Iago Longue; PEREIRA FILHO, Zander Ribeiro.

A produção acadêmica sobre a fabricação digital nas escolas brasileiras de arquitetura e urbanismo

e o ensino de arquitetura permanecem constantes, bem como sobre a modelagem paramétrica.

Quadro 8 - Temáticas abordadas no ano de 2013

Quadro 8-Temáticas abordadas no ano de $\mathbf{2 0 1 3}$
\begin{tabular}{|c|c|c|}
\hline Eixo de discussão & Quantidade & Autores \\
\hline Análise digital da arquitetura moderna & 01 & Tagliari e Florio (2013) \\
\hline Fabricação digital e arquitetura efêmera & 01 & Miotto e Pupo (2013) \\
\hline Modelagem paramétrica & 01 & Maso (2013) \\
\hline Tecnologia e ensino de projeto & 01 & Costa (2013) \\
\hline
\end{tabular}

Fonte: Os autores.

No ano de 2014, conforme mostrado pelo Quadro 9, a tendência de exploração das tecnologias voltadas para o ensino e como forma de se compreender obras modernas se manteve, porém houve discussões a respeito do pensamento paramétrico e a complexidade dos processos de projeto envolvendo tal temática.

Quadro 9- Temáticas abordadas no ano de 2014
\begin{tabular}{|c|c|c|}
\hline Eixo de discussão & Quantidade & Autores \\
\hline $\begin{array}{c}\text { Complexidade e pensamento } \\
\text { paramétrico }\end{array}$ & 02 & $\begin{array}{c}\text { Nojimoto (2014); } \\
\text { Soares (2014) }\end{array}$ \\
\hline Tecnologia e ensino de projeto & 02 & $\begin{array}{c}\text { Cardoso e Romcy (2014); } \\
\text { Celani (2014) }\end{array}$ \\
\hline Análise digital da arquitetura moderna & 01 & Florio (2014) \\
\hline
\end{tabular}
Fonte: Os autores.

Segundo o Quadro 10, fica explícito que no ano de 2015, com a expansão do volume de publicações a respeito do eixo das tecnologias digitais na arquitetura, também houve uma multiplicação das abordagens, passando a contemplar assuntos como inclusão de pessoas portadoras de necessidades específicas a partir da produção de modelos táteis, além do retorno do enfoque sobre habitações populares.

\begin{tabular}{|c|c|c|} 
Quadro 10 - Temáticas abordadas no ano de 2015 & Quantidade & Autores \\
\hline Eixo de discussão & 06 & $\begin{array}{c}\text { Alves e Trujillo (2015); } \\
\text { Bastitello et al. (2015); } \\
\text { Leite e Martins (2015); } \\
\text { Lima, Sousa e Romcy (2015); } \\
\text { Sperling et al. (2015); } \\
\text { Tramontano (2015) }\end{array}$ \\
\hline Fecnologia e ensino de projeto & 02 & $\begin{array}{c}\text { Passaro e Henriques (2015); } \\
\text { Passaro e Rohde (2015) }\end{array}$ \\
\hline Fabricação digital e inclusão & 02 & $\begin{array}{c}\text { Bem e Pupo (2015); } \\
\text { Sperling, Vandier e Scheeren (2015) }\end{array}$ \\
\hline Modelagem paramétrica & 01 & Pinto e Pupo (2015) \\
\hline $\begin{array}{c}\text { Fabricação digital e intervenção em } \\
\text { estruturas pré-existentes }\end{array}$ & 01 & Schunemann e Celani (2015) \\
\hline $\begin{array}{c}\text { Modelagem, digitalização 3D e } \\
\text { prototipagem rápida }\end{array}$ & 01 & Bastiani e Pupo (2015) \\
\hline Prototipagem rápida & 01 & Tramontano e Pereira Junior (2015) \\
\hline $\begin{array}{c}\text { Interface da modelagem digital em BIM } \\
\text { com prototipagem rápida }\end{array}$ & 01 & Calixto, Morais e Ruschel (2015) \\
\hline
\end{tabular}

Fonte: Os autores.

No ano de 2016, de acordo com o exposto pelo Quadro 11, a diversidade de escopos de discussão se manteve, mesmo com a queda nas produções a respeito da temática. A questão da modelagem paramétrica recebeu grande atenção neste ano, totalizando seis publicações. 
MARTINS, Iago Longue; PEREIRA FILHO, Zander Ribeiro.

A produção acadêmica sobre a fabricação digital nas escolas brasileiras de arquitetura e urbanismo

Quadro 11 - Temáticas abordadas no ano de 2016
\begin{tabular}{|c|c|c|}
\hline Eixo de discussão & Quantidade & $\begin{array}{c}\text { Autores } \\
\text { Modelagem paramétrica }\end{array}$ \\
& 06 & $\begin{array}{c}\text { Arcal6); } \\
\text { Digiandomenico, Landim e Fischer } \\
(2016) ; \\
\text { Duarte, Lepri e Sanches (2016); } \\
\text { Quintella, Florêncio e Ferreira (2016); } \\
\text { Sedrez (2016); } \\
\text { Teribele (2016) }\end{array}$ \\
\hline Fabricação digital & & Miotto (2016) \\
\hline Fabricação digital e arquitetura efêmera & 01 & Miyasaka, Paoletti e Fabrício (2016) \\
\hline Fabricação digital e habitação popular & 01 & Nardelli e Backheuser (2016) \\
\hline Tecnologia e ensino de projeto & 01 & Tramontano et al. (2016) \\
\hline
\end{tabular}

Fonte: Os autores.

Conforme mostrado pelo Quadro 12, no ano de 2017 a tendência de queda se manteve e o enfoque se voltou para a questão do ensino de projeto de arquitetura aliado às novas tecnologias, graças ao interesse de novas instituições em compreender como é possível associar tal inovação com a rotina dos próprios cursos de arquitetura.

Quadro 12 - Temáticas abordadas no ano de 2017

\begin{tabular}{|c|c|c|}
\hline Eixo de discussão & Quantidade & Autores \\
\hline Tecnologia e ensino de projeto & 04 & $\begin{array}{c}\text { Braida et al. (2017); } \\
\text { Celani et al. (2017); } \\
\text { Frosch e Alves (2017); } \\
\text { Romcy (2017) }\end{array}$ \\
\hline Fabricação digital & 01 & Alcântara Filho e Mendes (2017) \\
\hline Fabricação digital e detalhamento & 01 & Castrioto et al. (2017) \\
\hline Modelagem digital & 01 & Campos e Celani (2017) \\
\hline Modelagem paramétrica & 01 & Silva (2017) \\
\hline
\end{tabular}

Já no ano de 2018, de acordo com o Quadro 13, observa-se uma continuidade de temas frequentemente abordados no período analisado, como a modelagem paramétrica e a tecnologia voltada para o ensino de projeto. Entretanto, foi identificado um novo eixo de discussão, que trata especificamente do movimento maker, o que indica uma evolução da complexidade das abordagens, que passam a extravasar as relações de ensino-aprendizagem e de prática profissional para abrangerem, também, a influência que as novas tecnologias possuem na reorganização das estruturas de trabalho e economia.

Quadro 13 - Temáticas abordadas no ano de 2018

\begin{tabular}{|c|c|c|}
\hline Eixo de discussão & Quantidade & Autores \\
\hline Fabricação digital & 01 & Scheeren e Sperling (2018) \\
\hline Fabricação digital e o movimento maker & 01 & Campos e Dias (2018) \\
\hline $\begin{array}{c}\text { Modelagem, digitalização 3D e } \\
\text { prototipagem rápida }\end{array}$ & 02 & $\begin{array}{l}\text { Almeida (2018); } \\
\text { Martins (2018) }\end{array}$ \\
\hline Modelagem paramétrica & 02 & $\begin{array}{l}\text { Cartana, Pereira e Mayer (2018); } \\
\text { Sanches, Abdalla e Alberto (2018) }\end{array}$ \\
\hline Tecnologia e ensino de projeto & 02 & $\begin{array}{l}\text { Omena, Lara e Oliveira (2018); } \\
\text { Lima, Pisani e Villac (2018) }\end{array}$ \\
\hline
\end{tabular}

Fonte: Os autores.

Por fim, após a realização da quantificação anual por eixo de discussão, foi feito um somatório total, conforme mostrado no Quadro 14, considerando também o agrupamento de eixos correlatos em macrocategorias de pesquisa, com o intuito de verificar quais temáticas foram mais exploradas no Brasil durante o período de 2009 a 2018. 
MARTINS, Iago Longue; PEREIRA FILHO, Zander Ribeiro.

A produção acadêmica sobre a fabricação digital nas escolas brasileiras de arquitetura e urbanismo

\begin{tabular}{|c|c|c|c|c|}
\hline Macrocategorias de pesquisa & Totalização & Eixos de discussão & Quantidade & $\begin{array}{c}\text { Ano da } \\
\text { publicação } \\
\text { mais recente } \\
\end{array}$ \\
\hline Tecnologia e ensino de projeto & 21 & Tecnologia e ensino de projeto & 21 & 2018 \\
\hline \multirow{8}{*}{ Fabricação digital } & \multirow{8}{*}{19} & Fabricação digital & 6 & 2018 \\
\hline & & Fabricação digital e o movimento maker & 1 & 2018 \\
\hline & & Fabricação digital e detalhamento & 1 & 2017 \\
\hline & & Fabricação digital e habitação popular & 4 & 2016 \\
\hline & & Fabricação digital e arquitetura efêmera & 2 & 2016 \\
\hline & & Fabricação digital e inclusão & 2 & 2015 \\
\hline & & $\begin{array}{c}\text { Fabricação digital e intervenção em } \\
\text { estruturas pré-existentes }\end{array}$ & 1 & 2015 \\
\hline & & Fabricação digital e prática profissional & 2 & 2009 \\
\hline \multirow{3}{*}{$\begin{array}{l}\text { Modelagem paramétrica, } \\
\text { complexidade e pensamento } \\
\text { paramétrico }\end{array}$} & \multirow{3}{*}{18} & Modelagem paramétrica & 15 & 2018 \\
\hline & & Complexidade e pensamento paramétrico & 2 & 2014 \\
\hline & & $\begin{array}{c}\text { Modelagem paramétrica e habitação } \\
\text { popular }\end{array}$ & 1 & 2011 \\
\hline \multirow{5}{*}{$\begin{array}{l}\text { Modelagem, digitalização 3D e } \\
\text { prototipagem rápida }\end{array}$} & \multirow{5}{*}{11} & $\begin{array}{c}\text { Modelagem, digitalização 3D e } \\
\text { prototipagem rápida }\end{array}$ & 5 & 2018 \\
\hline & & Modelagem digital & 1 & 2017 \\
\hline & & Prototipagem rápida & 2 & 2015 \\
\hline & & $\begin{array}{l}\text { Interface da modelagem digital em BIM com } \\
\text { prototipagem rápida }\end{array}$ & 1 & 2015 \\
\hline & & Análise digital da arquitetura moderna & 2 & 2014 \\
\hline
\end{tabular}

Fonte: Os autores.

É possível perceber que os eixos de discussão mais explorados no período em análise correspondem a questões com escopo abrangente, como "tecnologia e ensino de projeto", "modelagem paramétrica" e "fabricação digital”, o que permite o desenvolvimento de diferentes abordagens e explorações a respeito do assunto. Em contrapartida, eixos muito específicos, como "modelagem paramétrica e habitação popular" e "fabricação digital e estruturas pré-existentes", foram pouco abordados entre os anos de 2009 e 2018.

Sob a ótica das macrocategorias de pesquisa, observa-se a mesma tendência de popularidade dos escopos abrangentes, já que as três macrocategorias que mais concentraram publicações são "tecnologia e ensino de projeto", "fabricação digital" e "modelagem paramétrica, complexidade e pensamento paramétrico". Seguindo esse mesmo padrão, a macrocategoria "modelagem, digitalização 3D e prototipagem rápida", que possui um recorte temático especializado, ainda não foi tão explorada quanto as demais, agrupando cerca de duas vezes menos material bibliográfico que a macrocategoria "tecnologia e ensino de projeto", em primeiro lugar.

Isso demonstra que a fabricação digital vem, de modo geral, passando por um processo de estudo e compreensão nas instituições acadêmicas brasileiras, para depois culminar em análises de aplicações mais específicas dessas tecnologias no contexto arquitetônico, o que indica um amadurecimento dos estudos a esse respeito. Nesse sentido, a recorrência das publicações a respeito da fabricação digital na arquitetura e o constante surgimento de novas linhas de estudo mais especializadas também apontam para uma consolidação desse tema como um elemento de interesse para o meio acadêmico brasileiro.

\section{Análise paralela dos cenários}

Conforme descrito por Pupo (2008), o cenário da pesquisa e ensino da prototipagem rápida para arquitetura no Brasil ao final da primeira década do século XXI era bastante limitado, devido a fatores de ordem econômica, como os altos preços dos 
equipamentos e insumos, que eram importados dos Estados Unidos, da China e de países da Europa, além de fatores de ordem social, pela indisponibilidade de mão de obra especializada.

Além disso, a autora registrou que, no período, só havia três instituições equipadas com um laboratório de prototipagem rápida, sendo elas a Universidade de Brasília (UNB), a Universidade Presbiteriana Mackenzie e a Universidade Estadual de Campinas (UNICAMP). Tais laboratórios se dedicavam a linhas de pesquisa voltadas para a prototipagem rápida, fabricação digital, análise digital de obras de arquitetura moderna e digitalização 3D.

Atualmente, de acordo com os resultados trazidos por esta pesquisa, a inserção da fabricação digital como método construtivo ainda é limitada no país, porém grandes avanços aconteceram no âmbito da abordagem acadêmica do assunto, devido à multiplicação dos laboratórios de prototipagem rápida vinculados às escolas de arquitetura, bem como das instituições que possuem, pelo menos, alguma ferramenta que possibilite a fabricação digital, como a impressora 3D. Segundo os trabalhos coletados, são, no mínimo, 15 instituições equipadas com tal maquinário, distribuídas pelas regiões Centro-Oeste, Nordeste, Sudeste e Sul, porém com uma maior concentração no Sudeste.

Este avanço detectado é resultante da queda de uma das barreiras descritas por Pupo (2008): a questão econômica. Após a crise de 2008, o preço dos equipamentos importados reduziu e algumas patentes venceram, abrindo espaço para a produção nacional de tais tecnologias (SPERLING et al., 2015), o que facilitou a proliferação dos laboratórios de técnicas digitais no Brasil.

Este aumento da quantidade de centros de pesquisa também impactou na quantidade de linhas de pesquisa, que se ampliaram e tornaram-se mais especializadas, com surgimento de estudos voltados para o desenho paramétrico, a prototipagem rápida e o ensino de projeto, a fabricação digital e habitação popular, o desenho paramétrico e habitação, a fabricação digital e arquitetura efêmera, além da prototipagem rápida e inclusão.

\section{Conclusão}

O método de revisão sistemática de literatura permitiu conhecer o estado da arte das publicações acadêmicas sobre a fabricação digital na arquitetura no Brasil e como este cenário evoluiu desde o estudo realizado por Pupo (2008).

Após as análises comparativas estabelecidas ao longo do artigo, pode-se perceber que houve uma popularização da temática da fabricação digital na arquitetura nas instituições acadêmicas brasileiras, o que demonstra que as escolas estão abrindo espaço para que mais profissionais fluentes nas tecnologias digitais sejam formados. Este fator, com o tempo, eliminará a barreira social descrita por Pupo (2008), que é a falta de profissionais habilitados para implementar essas inovações na construção civil, e permitirá que o Brasil também se destaque na cena mundial com a produção de uma arquitetura de melhor qualidade, pela precisão na execução dos projetos, além da possibilidade de construção de formas e estruturas mais complexas, com métodos construtivos inovadores e de baixo impacto ambiental.

Ademais, percebe-se que houve um crescente interesse em explorar diferentes nichos de aplicação das tecnologias digitais de fabricação na arquitetura, abrangendo questões como habitação popular, arquitetura efêmera e intervenções em estruturas já 
existentes, o que demonstra uma contribuição da academia brasileira para a compreensão da aplicabilidade das novas tecnologias no meio arquitetônico.

\section{Referências}

ALCÂNTARA FILHO, Jorge; MENDES, Letícia. Um experimento de fabricação digital: parametrização, prototipagem e fabricação de painel. Revista Geometria Gráfica, Recife: UFPE, v. 1, n. 1, 2017, p. 81-98. Disponível em: https://periodicos.ufpe.br/revistas/geometriagrafica/article/view/236127. Acesso em: 21 jan. 2019.

ALMEIDA, Caio Augusto Rabite de. Tectônicas digitais: a (in)tangibilidade no processo de projeto em arquitetura. 2018. Dissertação (Mestrado em Ambiente Construído) - Faculdade de Engenharia, Universidade Federal de Juiz de Fora, Juiz de Fora, 2018. Disponível em: https://repositorio.ufjf.br/jspui/handle/ufjf/8218. Acesso em: 21 jan. 2019.

ALVES, Gilfranco; TRUJILLO, Juliana. Processos digitais de projeto: mudança de paradigma no ensino da Arquitetura e Urbanismo. In: SEMINÁRIO PROJETAR, 7., 2015, Recife. Anais [...]. Recife: Grupo Projetar UFRN, 2015.p. 131-142.

ARCARI, Etiene do Amaral. Fluxo de trabalho de interoperabilidade entre modelagem, materialização e reutilização aplicado em detalhe projetual de acessibilidade. 2016. Dissertação (Mestrado em Arquitetura e Urbanismo) - Centro Tecnológico, Universidade Federal de Santa Catarina, Florianópolis, 2016. Disponível em: https://repositorio.ufsc.br/handle/123456789/168060. Acesso em: 21 jan. 2019.

BARBOSA NETO, Wilson; ARAÚJO, André; CELANI, Gabriela. Modelagem paramétrica para o projeto e produção automatizados de uma peça de mobiliário: um exercício de aplicação. In: CONGRESSO INTERNACIONAL DA SOCIEDADE IBEROAMERICANA DE GRÁFICA DIGITAL, 16., 2012, Fortaleza. Anais [...]. Fortaleza: SIGRADI, 2012. Disponível em: http://cumincades.scix.net/data/works/att/sigradi2012_54.content.pdf. Acesso em: 21 jan. 2019.

BASTIANI, Jamile; PUPO, Regiane. Materializar para informar e conscientizar. In: CONGRESSO INTERNACIONAL DA SOCIEDADE IBEROAMERICANA DE GRÁFICA DIGITAL, 19., 2015, Florianópolis. Proceedings [...]. São Paulo: Editora Blucher, 2015. p. 161-166. Disponível em: http://pdf.blucher.com.br.s3-sa-east-

1.amazonaws.com/designproceedings/sigradi2015/30394.pdf. Acesso em: 21 jan. 2019.

BATISTELLO, Paula; BALZAN, Katiane Laura; PIAIA, Luana Peroza; MIOTTO, Juliano. Prototipagem rápida e fabricação digital em ateliê vertical: do processo à materialização. In: CONGRESSO INTERNACIONAL DA SOCIEDADE IBEROAMERICANA DE GRÁFICA DIGITAL, 19., 2015, Florianópolis. Proceedings [...]. São Paulo: Editora Blucher, 2015. p. 137-142. Disponível em: http://pdf.blucher.com.br.s3-sa-east-

1.amazonaws.com/designproceedings/sigradi2015/30300.pdf. Acesso em: 21 jan. 2019.

BEM, Gabriel Moraes; PUPO, Regiane Trevisan. Imprimindo o espaço para as pessoas com deficiência visual: uma revisão sistemática. In: CONGRESSO INTERNACIONAL DA SOCIEDADE IBEROAMERICANA DE GRÁFICA DIGITAL, 19., 2015, Florianópolis. Proceedings [...]. São Paulo: Editora Blucher, 2015. p. 148-152. Disponível em:

http://pdf.blucher.com.br.s3-sa-east-1.amazonaws.com/designproceedings/sigradi2015/30370.pdf. Acesso em: 21 jan. 2019.

BORGES, Marina Ferreira. Fabricação Digital no Brasil e as possibilidades de mudança de paradigma no setor da construção civil. Ambiente Construído, Porto Alegre, v. 16, n. 4, p. 79-91, 2016. DOI: https://dx.doi.org/10.1590/s1678$\underline{86212016000400106 .}$

BOTHA, Marcel; SASS, Lawrence. The Instant House: design and digital fabrication of housing for developing environments. Cambridge, Massachusetts: Massachusetts Institute of Technology, 2006.

BRAIDA, Frederico; AZEVEDO, Cheyenne; FERREIRA, Izabela; CASTRO, Janaina; PEREIRA, Luiz. Projetando com blocos de montar: Residências mínimas no contexto da arquitetura contemporânea. In: CONGRESSO INTERNACIONAL DA SOCIEDADE IBEROAMERICANA DE GRÁFICA DIGITAL, 21., 2017, Concepción. Proceedings [...]. São Paulo: Editora Blucher, 2017. Disponível em: http://pdf.blucher.com.br.s3-sa-east1.amazonaws.com/designproceedings/sigradi2017/048.pdf. Acesso em: 21 jan. 2019. 
BRUSCATO, Underlea Miotto; ALVARADO, Rodrigo García; MONTOYA, Claudio Labarca. Arquitetos com aventais: revisão de três experiências de arquitetura e fabricação digital e suas mudanças profissionais. In: SEMINÁRIO PROJETAR, 4., 2009, São Paulo. Anais [...]. São Paulo: UPM, 2009. Disponível em:

https://www.ufrgs.br/parametricodesign/wp-content/uploads/2017/09/9_projetar_aventais1.pdf. Acesso em: 21 jan. 2019 .

CALIXTO, Victor; MORAIS, Euler José de Oliveira; RUSCHEL, Regina Coeli. Incorporação de modelagem da informação em prototipagem digital. In: ENCONTRO DE TECNOLOGIA DE INFORMAÇÃO E COMUNICAÇÃO NA CONSTRUÇÃO, 7., 2015, Recife. Proceedings [...]. São Paulo: Editora Blucher, 2015. Disponível em: http://pdf.blucher.com.br.s3-sa-east-1.amazonaws.com/engineeringproceedings/tic2015/042.pdf. Acesso em: 21 jan. 2019 .

CAMPOS, Filipe Medeia de; CELANI, Gabriela. Subdivisão de formas livres em arquitetura com o objetivo de viabilização de sua fabricação: métodos e aplicações. Interações (Campo Grande), v. 18, n. 3, Campo Grande, 2017, p. 3-22. DOI: http://dx.doi.org/10.20435/inter.v18i3.1463.

CAMPOS, Paulo Eduardo Fonseca de; DIAS, José Henrique dos Santos. A insustentável neutralidade da tecnologia: o dilema do Movimento Maker e dos Fab Labs. Liinc em Revista, Rio de Janeiro, v. 14, n. 1, p. 33-46, maio 2018. Disponível em: http://revista.ibict.br/liinc/article/view/4152. Acesso em: 21 jan. 2019.

CANNAERTS, Corneel. Models of/Models for Architecture: Physical and Digital Modelling in Early Design Stages. In: CONFERENCE FOR EDUCATION AND RESEARCH IN COMPUTER AIDED ARCHITECTURAL DESIGN IN EUROPE, 27., 2009, Istanbul. Proceedings [... ]. Istanbul, 2009. p. 781-786.

CARDOSO, Daniel Ribeiro; ROMCY, Neliza Maria e Silva. Reflexões e novas práticas para a inserção dos meios digitais nos cursos de arquitetura, urbanismo e design: o relato de uma experiência. In: ENCONTRO DA ASSOCIAÇÃO NACIONAL DE PESQUISA E PÓS-GRADUAÇÃO EM ARQUITETURA E URBANISMO, 3., 2014 , São Paulo. Anais [...]. São Paulo: ANPARQ, 2014. Disponível em: http://www.anparq.org.br/dvd-enanparq-3/htm/Artigos/ST/STNPNT-004-4-CARDOSO.ROMCY.pdf. Acesso em: 21 jan. 2019.

CARTANA, Rafael Prado; PEREIRA, Fernando Oscar Ruttkay; MAYER, Adir. Estudo piloto para elementos de controle solar desenvolvidos com modelagem paramétrica e fabricação digital. Ambiente Construído, Porto Alegre, v. 18, $\mathrm{n}$. 3, 2018. DOI: http://dx.doi.org/10.1590/s1678-86212018000300268.

CASTRIOTO, Caio Magalhães; CARVALHO, Guilherme Giantini da Silva; CÔCO JUNIOR, Verly Henry; CELANI, Gabriela. O futuro do detalhamento arquitetônico: concepção e representação na era digital, e impactos para a formação dos arquitetos. Revista Geometria Gráfica, Recife: UFPE, v. 1, n. 1, 2017. Disponível em:

https://periodicos.ufpe.br/revistas/geometriagrafica/article/view/236123. Acesso em: 21 jan. 2019.

CELANI, Gabriela. O LAPAC e o grupo Teorias e Tecnologias Contemporâneas aplicadas ao Projeto. In: ENCONTRO DA ASSOCIAÇÃO NACIONAL DE PESQUISA E PÓS-GRADUAÇÃO EM ARQUITETURA E URBANISMO, 3., 2014, São Paulo. Anais [...]. São Paulo: ANPARQ, 2014. Disponível em: http://www.anparq.org.br/dvd-enanparq3/htm/Artigos/ST/ST-NPNT-004-1-CELANI.pdf. Acesso em: 21 jan. 2019.

CELANI, Gabriela. Teorías y tecnologías en la arquitectura contemporánea: el Laboratorio de Automatización y Prototipos de Arquitectura y Construcción de la Universidad Estatal de Campinas, Brasil. Revista de Arquitectura, Santiago: Facultad de Arquitectura y Urbanismo - Universidad de Chile, v. 18, 2012, p. 33-47. Disponível em: https://revistas.uchile.cl/index.php/RA/article/view/32539. Acesso em: 21 jan. 2019.

CELANI, Gabriela; MONTEIRO, Ana Maria Góes; FRANCO, Juarez; CALIXTO, Victor. Integração de tecnologias CAD/CAE/CAM no ateliê de arquitetura: Uma aplicação no projeto de edifícios altos. Gestão e Tecnologia de Projetos, São Paulo: USP, v. 12, n. 1, 2017, p. 29-52. DOI: https://doi.org/10.11606/gtp.v12i1.99222.

CELANI, Gabriela; PICCOLI, Valéria. As funções de uma maquete. Arquitetura Revista, São Leopoldo: UNISINOS, v. 6, n. 1, 2010, p. 50-62. DOI: https://doi.org/10.4013/arq.2010.61.05. 
CHUA, C.K.; LEONG, K.F.; LIM, C.S..Rapid Prototyping: Principles and Applications. 3. ed. Cingapura: Nanyang Technological University, 2010.

COSTA, Fernando José de Medeiros. Do modelo geométrico ao modelo físico: o tridimensional na educação do arquiteto e urbanista. 2013. Dissertação (Mestrado em Arquitetura e Urbanismo) - Universidade Federal do Rio Grande do Norte, Natal, 2013. Disponível em: http://repositorio.ufrn.br:8080/jspui/handle/123456789/12312. Acesso em: 21 jan. 2019.

DIGIANDOMENICO, Dyego; LANDIM, Gabriele; FISCHER, Henrique. Trançado: recursos computacionais aplicados no processo de projeto de mobiliário urbano. In: CONGRESSO INTERNACIONAL DA SOCIEDADE IBEROAMERICANA DE GRÁFICA DIGITAL, 20., 2016, Buenos Aires. Proceedings [...]. Buenos Aires: SIGRADI, 2016. Disponível em: http://papers.cumincad.org/data/works/att/sigradi2016_417.pdf. Acesso em: 21 jan. 2019.

DUARTE, Rovenir Bertola; LEPRI, Louisa Savignon; SANCHES, Malu Magalhães. Objectile e o projeto paramétrico. In: CONGRESSO INTERNACIONAL DA SOCIEDADE IBEROAMERICANA DE GRÁFICA DIGITAL, 20., 2016, Buenos Aires.

Proceedings [...]. São Paulo: Editora Blucher, 2016. p. 149-156. Disponível em: http://pdf.blucher.com.br.s3-sa-east1.amazonaws.com/designproceedings/sigradi2016/710.pdf. Acesso em: 21 jan. 2019.

FLORIO, Wilson. Modelagem Paramétrica em Arquitetura: Estratégias para Materializar Formas Complexas. In: CONGRESSO INTERNACIONAL DA SOCIEDADE IBEROAMERICANA DE GRÁFICA DIGITAL, 13., 2009, São Paulo. Proceedings [...]. São Paulo: SIGRADI, 2009. Disponível em: http://papers.cumincad.org/data/works/att/sigradi2009_792.content.pdf. Acesso em: 21 jan. 2019.

FLORIO, Wilson. Modelagem paramétrica, criatividade e projeto: duas experiências com estudantes de arquitetura. Gestão e Tecnologia de Projetos, São Paulo: USP, v. 6, n. 2, 2011, p. 43-66. DOI: https://doi.org/10.4237/gtp.v6i2.211.

FLORIO, Wilson. Raciocínio Analógico Paramétrico: uma experiência criativa em arquitetura. In: CONGRESSO INTERNACIONAL DA SOCIEDADE IBEROAMERICANA DE GRÁFICA DIGITAL, 15., 2011, Santa Fé. Proceedings [...]. Santa Fé: SIGRADI, 2011. Disponível em: http://papers.cumincad.org/data/works/att/sigradi2011_086.content.pdf. Acesso em: 21 jan. 2019.

FLORIO, Wilson. Notas sobre Pensamento e Cognição em Projetos Paramétricos. In: ENCONTRO DA ASSOCIAÇÃO NACIONAL DE PESQUISA E PÓS-GRADUAÇÃO EM ARQUITETURA E URBANISMO, 2., 2012, Natal. Anais [...]. Natal: ANPARQ, 2012.

FLORIO, Wilson. Reflexão sobre residências emblemáticas a partir de simulações estáticas/dinâmicas e a fabricação digital. In: CONGRESSO INTERNACIONAL DA SOCIEDADE IBEROAMERICANA DE GRÁFICA DIGITAL, 18., 2014, Montevideo. Proceedings [...]. São Paulo: Editora Blucher, 2014. p. 311-315. Disponível em: http://papers.cumincad.org/cgi-bin/works/paper/sigradi2014_018. Acesso em: 21 jan. 2019.

FLORIO, Wilson; TAGLIARI, Ana. Fabricação de maquetes físicas: tangibilidade no processo de projeto em Arquitetura. Exacta - Engenharia de Produção, São Paulo, v. 9, n. 1, p. 125-136, 2011. DOI: https://doi.org/10.5585/exactaep.vgn1.2420.

FROSCH, Renato; ALVES, Antonio Fernando Gomes. Perspectivas para a formação docente universitária com aspectos makers. Revista Estudos Aplicados em Educação, São Caetano do Sul: Universidade Municipal de São Caetano do Sul, v. 2, n. 4, 2017. DOl: http://dx.doi.org/10.13037/rea-e.vol2n4.4997.

GONÇALVES, Eliseu Manuel Vieira. A Linguagem da Gravidade - Para uma Reflexão sobre o Ensino da Razão e Ser dos Elementos Arquitectónicos Estruturais. Trabalho de Síntese. Porto: Universidade do Porto, 2005.

KOLAREVIC, Branko. Architecture in the Digital Age: Design and Manufacturing. London: Spon Press, 2003.

KOLAREVIC, Branko. Digital Fabrication: Manufacturing Architecture in the Information Age. In: ANNUAL CONFERENCE OF THE ASSOCIATION FOR COMPUTER AIDED DESIGN IN ARCHITECTURE, 2001, Buffalo. Proceedings [...]. Buffalo: ACADIA, 2001. p. 268-277. 
LARA, Arthur Hunold; CANELLA, Eduardo Gorge; GIACAGLIA, Marcelo Eduardo; MOURA, Norberto Corrêa da Silva. Brinquedos, modelos: uma atividade lúdica se transforma em curricular com apoio das novas tecnologias de fabricação digital. In: CONGRESSO INTERNACIONAL DA SOCIEDADE IBEROAMERICANA DE GRÁFICA DIGITAL, 14., 2010, Bogotá. Proceedings [...]. Bogotá: SIGRADI, 2010. Disponível em:

http://papers.cumincad.org/data/works/att/sigradi2010_73.content.pdf. Acesso em: 21 jan. 2019.

LAVERDE, Albenise; OLIVEIRA, Cláudia Terezinha de Andrade. As Atividades Experimentais no Contexto Acadêmico: O Confronto entre o Projeto e a Materialidade. São Paulo: FAUUSP, 2014.

LEITE, Denivaldo Pereira; MARTINS, Júlia Tenuta. Processos projetuais emergentes: A utilização de Design Digital e Prototipagem Rápida aplicados em Extensão Universitária. In: CONGRESSO INTERNACIONAL DA SOCIEDADE IBEROAMERICANA DE GRÁFICA DIGITAL, 19., 2015, Florianópolis. Proceedings [...]. São Paulo: Editora Blucher, 2015. p. 558-563. Disponível em: http://pdf.blucher.com.br.s3-sa-east-

1.amazonaws.com/designproceedings/sigradi2015/100220.pdf. Acesso em: 21 jan. 2019.

LIMA, Ana Gabriela Godinho; PISANI, Maria Augusta Justi; VILLAC, Maria Isabel. Considerações para a "Cultura de Projeto". Caderno de Pós-Graduação em Arquitetura e Urbanismo, São Paulo: FAU Mackenzie, v. 18, n. 1, p. 7-18, 2018. DOI: https://dx.doi.org/10.5935/cadernosarquitetura.v18n1p7-18.

LIMA, Fernanda; MEIRELLES, Célia Regina Moretti; FLORIO, Wilson; CUGNASCA, Mariana. O potencial das novas tecnologias digitais e suas implicações no desenvolvimento de projetos de habitação em madeira, uma experimentação. In: SEMINÁRIO PROJETAR, 5., 2011, Belo Horizonte. Anais [...]. Belo Horizonte: Grupo Projetar UFMG, 2011.

LIMA, Pedro Gabriel de Sousa; SOUSA, Débora de Oliveira; ROMCY, Neliza Maria e Silva. Bases epistemológicas para uma abordagem contemporânea ao ensino de projeto. Os meios digitais, o profissional reflexivo e a ruptura dos velhos paradigmas. In: CONGRESSO INTERNACIONAL DA SOCIEDADE IBEROAMERICANA DE GRÁFICA DIGITAL, 19., 2015, Florianópolis. Proceedings [...]. São Paulo: Editora Blucher, 2015. p. 602-608. Disponível em:

http://pdf.blucher.com.br.s3-sa-east-1.amazonaws.com/designproceedings/sigradi2015/100377.pdf. Acesso em: 21 jan. 2019.

MARTINS, lago Longue. Oceanário de Vitória: explorando a fabricação digital na arquitetura. 2018. Trabalho de Conclusão de Curso (Bacharelado em Arquitetura e Urbanismo) - Instituto Federal de Educação, Ciência e Tecnologia Fluminense, Campos dos Goytacazes, 2018. Disponível em:

http://bd.centro.iff.edu.br/handle/123456789/2143. Acesso em: 21 jan. 2019.

MASO, Thiago Albino. Uso de novas tecnologias na formação do espaço contemporâneo. 2013. Trabalho de Conclusão de Curso (Bacharelado em Engenharia de Produção Civil) - Universidade Tecnológica Federal do Paraná, Curitiba, 2013. Disponível em: http://repositorio.roca.utfpr.edu.br/sspui/handle/1/2155. Acesso em: 21 jan. 2019.

MIOTTO, Juliano. Fabricação digital na arquitetura efêmera, de estandes em feiras comerciais, aplicada em visual merchandising. 2016. Dissertação (Mestrado em Arquitetura e Urbanismo) - Centro Tecnológico, Universidade Federal de Santa Catarina, Florianópolis, 2016. Disponível em: https://repositorio.ufsc.br/handle/123456789/167739. Acesso em: 21 jan. 2019.

MIOTTO, Juliano; PUPO, Regiane Trevisan. Fabricação Digital na Arquitetura Efêmera: Aplicação em Feiras Comerciais. In: CONGRESSO INTERNACIONAL DA SOCIEDADE IBEROAMERICANA DE GRÁFICA DIGITAL, 17., 2013, Valparaíso. Proceedings [...]. São Paulo: Editora Blucher, 2013. Disponível em:

http://papers.cumincad.org/data/works/att/sigradi2013_391.content.pdf. Acesso em: 21 jan. 2019.

MIYASAKA, Elza Luli; PAOLETTI, Ingrid; FABRÍCIO, Marcio Minto. Choosing the partner in a Digital Fabrication Case. In: CONGRESSO INTERNACIONAL DA SOCIEDADE IBEROAMERICANA DE GRÁFICA DIGITAL, 20., 2016, Buenos Aires. Proceedings [...]. São Paulo: Editora Blucher, 2016. p. 374-381.

NARDELLI, Eduardo Sampaio; BACKHEUSER, Luiz Alberto Fresl. Sistema Wikihouse aplicado ao Programa Minha Casa Minha Vida. In: CONGRESSO INTERNACIONAL DA SOCIEDADE IBEROAMERICANA DE GRÁFICA DIGITAL, 20., 
2016, Buenos Aires. Anais [...]. Buenos Aires: SIGRADI, 2016. Disponível em:

http://papers.cumincad.org/data/works/att/sigradi2016_461.pdf. Acesso em: 21 jan. 2019.

NOJIMOTO, Cynthia. Construindo diálogos: complexidade e emergência em processos de design. 2014. Tese (Doutorado em Arquitetura e Urbanismo) - Instituto de Arquitetura e Urbanismo, Universidade de São Paulo, São Carlos, 2014. DOI: https://doi.org/10.11606/T.102.2016.tde-08032016-103306.

OLIVEIRA, Marina Rodrigues de. Modelagem virtual e prototipagem rápida aplicadas em projeto de arquitetura. 2011. Dissertação (Mestrado em Arquitetura e Urbanismo) - Escola de Engenharia de São Carlos, Universidade de São Paulo, São Carlos, 2011. Disponível em: http://www.teses.usp.br/teses/disponiveis/18/18141/tde-07042011110243/en.php. Acesso em: 21 jan. 2019.

OLIVEIRA, Marina Rodrigues; FABRÍCIO, Márcio Minto. Modelos físicos e virtuais como ferramentas de ensino de projeto de arquitetura: relato de uma vivência. In: CONGRESSO INTERNACIONAL DA SOCIEDADE IBEROAMERICANA DE GRÁFICA DIGITAL, 13., 2009, São Paulo. Proceedings [...]. São Paulo: SIGRADI, 2009. Disponível em: http://papers.cumincad.org/data/works/att/sigradi2009_816.content.pdf. Acesso em: 21 jan. 2019.

OMENA, Thiago Henrique; LARA, Arthur Hunold; OLIVEIRA, Claudia Terezinha de Andrade. Arquitetura algorítmica e as mudanças nos paradigmas de representação e documentação arquitetônica. Brazilian Applied Science Review, Curitiba, v. 3, n. 1, 2018, p. 227-246. Disponível em: http://www.brjd.com.br/index.php/BASR/article/view/726/614. Acesso em: 21 jan. 2019.

PASSARO, Andres; ROHDE, Clarice. Casa Revista: arquitetura de fonte aberta. In: CONGRESSO INTERNACIONAL DA SOCIEDADE IBEROAMERICANA DE GRÁFICA DIGITAL, 19., 2015, Florianópolis. Proceedings [...]. São Paulo: Editora Blucher, 2015. p. 70-76. Disponível em: http://pdf.blucher.com.br.s3-sa-east1.amazonaws.com/designproceedings/sigradi2015/30043.pdf. Acesso em: 21 jan. 2019.

PASSARO, Andres; HENRIQUES, Gonçalo Castro. Abrigos sensíveis, do método ao conceito, superando a instrumentalização. In: CONGRESSO INTERNACIONAL DA SOCIEDADE IBEROAMERICANA DE GRÁFICA DIGITAL, 19., 2015, Florianópolis. Proceedings [...]. São Paulo: Editora Blucher, 2015. p. 94-100. Disponível em:

http://pdf.blucher.com.br.s3-sa-east-1.amazonaws.com/designproceedings/sigradi2015/30155.pdf. Acesso em: 21 jan. 2019 .

PINTO, Yuri Assis; PUPO, Regiane. Explorando a ferramenta de programação em design: um estudo sobre grasshopper. In: CONGRESSO INTERNACIONAL DA SOCIEDADE IBEROAMERICANA DE GRÁFICA DIGITAL, 19., 2015, Florianópolis. Proceedings [...]. São Paulo: Editora Blucher, 2015. p. 686-690. Disponível em: http://pdf.blucher.com.br/designproceedings/sigradi2015/110392.pdf. Acesso em: 21 jan. 2019.

POLONINI, Flávia Biccas da Silva. Fabricação Digital para a Arquitetura e Construção no Brasil, utilizando o método Contouring. In: CONGRESSO INTERNACIONAL DA SOCIEDADE IBEROAMERICANA DE GRÁFICA DIGITAL, 13., 2009, São Paulo. Proceedings [...]. São Paulo: SIGRADI, 2009. Disponível em:

http://cumincades.scix.net/data/works/att/sigradi2009_930.content.pdf. Acesso em: 21 jan. 2019.

PUPO, Regiane Trevisan. Ensino da prototipagem rápida e fabricação digital para arquitetura e construção no Brasil: definições e estado da arte. PARC Pesquisa em Arquitetura e Construção, Campinas: FEC UNICAMP, v. 1, n. 3, 2008. DOI: https://doi.org/10.20396/parc.v1i3.8634511.

PUPO, Regiane Trevisan. Inserção da prototipagem e fabricação digitais no processo de projeto: um novo desafio para o ensino de arquitetura. 2009. Tese (Doutorado em Engenharia Civil) - Faculdade de Engenharia Civil, Universidade Estadual de Campinas, Campinas, 2009. Disponível em:

http://repositorio.unicamp.br/handle/REPOSIP/257723. Acesso em: 21 jan. 2019.

PUPO, Regiane; CELANI, Gabriela. Técnicas de Prototipagem Digital para Arquitetura. In: VIII INTERNATIONAL CONFERENCE ON GRAPHICS ENGINEERING FOR ARTS AND DESIGN, 8.; SIMPÓSIO NACIONAL DE GEOMETRIA DESCRITIVA E DESENHO TÉCNICO, 19., 2009, Bauru. Anais [...]. Bauru: ABEG, 2009. 
QUINTELLA, Ivvy Pedrosa Cavalcante Pessôa; FLORÊNCIO, Eduardo Quintella; FERREIRA, Ítalo Cintra. Making pavilions: Os pavilhões temporários no contexto das faculdades de arquitetura e urbanismo. In: CONGRESSO INTERNACIONAL DA SOCIEDADE IBEROAMERICANA DE GRÁFICA DIGITAL, 20., 2016, Buenos Aires. Proceedings [...]. São Paulo: Editora Blucher, 2016. p. 318-325. Disponível em: http://pdf.blucher.com.br.s3-sa-east1.amazonaws.com/designproceedings/sigradi2016/483.pdf. Acesso em: 21 jan. 2019.

ROMCY, Neliza Maria e Silva. Abordagem paramétrica e ensino de projeto: proposição de diretrizes metodológicas, considerando estratégias curriculares e o atelier de projeto. 2017. Tese (Doutorado em Arquitetura e Urbanismo) Centro de Tecnologia, Universidade Federal do Rio Grande do Norte, Natal, 2017. Disponível em: https://repositorio.ufrn.br/jspui/handle/123456789/24131. Acesso em: 21 jan. 2019.

SAMPAIO, Rosana; MANCINI, Marisa. Estudos de revisão sistemática: um guia para síntese criteriosa da evidência científica. Brazilian Journal of Physical Therapy, v. 11, n. 1, São Carlos, 2007, p. 83-89. DOI: https://dx.doi.org/10.1590/S1413-35552007000100013.

SANCHES, Leonardo; ABDALLA, José Gustavo Francis; ALBERTO, Klaus Chaves. As pesquisas sobre sistemas generativos: uma revisão sistemática de literatura. In: PARC Pesquisa em Arquitetura e Construção, v. 9, n. 2, Campinas, 2018, p. 133-151. DOI: https://doi.org/10.20396/parc.vgi2.8650200.

SASS, Larry; OWMAN, Rivka. Materializing design: the implications of rapid prototyping in digital design. Design Studies, v. 27, 2006, p. 325-355. DOI: https://doi.org/10.1016/j.destud.2005.11.009

SCHEEREN, Rodrigo; SPERLING, David M. Technological appropriation and socio-technical adequacy in South America: applications of digital fabrication in architecture and design. In: CONGRESSO INTERNACIONAL DA SOCIEDADE IBEROAMERICANA DE GRÁFICA DIGITAL, 22., 2018, São Carlos. Proceedings [...]. São Paulo: Editora Blucher, 2018. p. 1054-1061.

SCHUNEMANN, Frederick; CELANI, Gabriela. Integração entre analógico e digital na Arquitetura. In: CONGRESSO INTERNACIONAL DA SOCIEDADE IBEROAMERICANA DE GRÁFICA DIGITAL, 19., 2015, Florianópolis. Proceedings [...]. São Paulo: Editora Blucher, 2015. p. 126-128. Disponível em: http://pdf.blucher.com.br.s3-sa-east1.amazonaws.com/designproceedings/sigradi2015/30221.pdf. Acesso em: 21 jan. 2019.

SEDREZ, Maycon Ricardo. Arquitetura e complexidade: a geometria fractal como sistema generativo. 2016. Tese (Doutorado em Arquitetura, Tecnologia e Cidade) - Faculdade de Engenharia, Arquitetura e Urbanismo (FEC), Universidade Estadual de Campinas, Campinas, 2016. Disponível em:

http://repositorio.unicamp.br/handle/REPOSIP/258036. Acesso em: 21 jan. 2019.

SILVA, Luciano Santos da. Design paramétrico a partir da digitalização 3D de geometrias da natureza com padrão de crescimento espiral. 2017. Dissertação (Mestrado em Design) - Faculdade de Arquitetura, Universidade Federal do Rio Grande do Sul, Porto Alegre, 2017. Disponível em: http://www.lume.ufrgs.br/handle/10183/158341. Acesso em: 21 jan. 2019.

SILVA, Neander Furtado; BRIDGES, Alan Harold; LIMA, Ecilamar Maciel; MORAIS, Helen Rachel Aguiar; SILVA JÚNIOR, Félix Alves. A indústria da Construção Civil está Pronta para a Fabricação Digital e a Customização em Massa? Uma Pesquisa sobre um Caso Brasileiro. In: CONGRESSO INTERNACIONAL DA SOCIEDADE IBEROAMERICANA DE GRÁFICA DIGITAL, 13., 2009, São Paulo. Proceedings [...]. São Paulo: SIGRADI, 2009. Disponível em: http://cumincades.scix.net/data/works/att/sigradi2009_1079.content.pdf. Acesso em: 21 jan. 2019.

SILVA JÚNIOR, Félix Alves da. O uso de algoritmos e de sistemas paramétricos na concepção arquitetônica de pequenas residências. 2011. Dissertação (Mestrado em Arquitetura e Urbanismo) - Faculdade de Arquitetura e Urbanismo, Universidade de Brasília, Brasília, 2011. Disponível em:

http://www.repositorio.unb.br/handle/10482/8899. Acesso em: 21 jan. 2019.

SOARES, João Paulo Marquesini. Processo de Design em Arquitetura: complexidade e meios digitais. 2014. Dissertação (Mestrado em Arquitetura e Urbanismo) - Instituto de Arquitetura e Urbanismo, Universidade de São Paulo, São Carlos, 2014. DOI: https://doi.org/10.11606/D.102.2014.tde-08012015-091345. 
SOUZA, Marcela Tavares de; SILVA, Michelly Dias da; CARVALHO, Rachel de. Revisão integrativa: o que é e como fazer. Einstein, São Paulo, v. 8, n. 1, 2010. DOI: https://dx.doi.org/10.1590/s1679-45082010rw1134.

SPERLING, David; VANDIER, Inácio; SCHEEREN, Rodrigo. Sentir o espaço: projeto com modelos táteis. In: CONGRESSO INTERNACIONAL DA SOCIEDADE IBEROAMERICANA DE GRÁFICA DIGITAL, 19., 2015, Florianópolis. Proceedings [...]. São Paulo: Editora Blucher, 2015. p. 108-112. Disponível em: http://pdf.blucher.com.br.s3-sa-east1.amazonaws.com/designproceedings/sigradi2015/30201.pdf. Acesso em: 21 jan. 2019.

SPERLING, David; HERRERA POLO, Pablo; CELANI, Gabriela; SCHEEREN, Rodrigo. Fabricação Digital na América do Sul: um mapeamento de linhas de ação a partir da arquitetura e urbanismo. In: CONGRESSO INTERNACIONAL DA SOCIEDADE IBERO AMERICANA DE GRÁFICA DIGITAL, 19., 2015, Florianópolis. Proceedings [...]. São Paulo: Editora Blucher, 2015. p. 119-125.

TAGLIARI, Ana; FLORIO, Wilson. Investigação de espaços não-construídos por meio de fabricação digital de maquetes. In: INTERNATIONAL CONFERENCE ON GRAPHICS ENGINEERING FOR ARTS AND DESIGN, 10.; SIMPÓSIO NACIONAL DE GEOMETRIA DESCRITIVA E DESENHO TÉCNICO, 21., 2013, Florianópolis. Anais [...]. Florianópolis: ABEG, 2013.

TERIBELE, Alessandra. Arquitetura com sistema pré-fabricado modular volumétrico: modelo generativo e diretrizes de fixação. 2016. Tese (Doutorado em Arquitetura) - Faculdade de Arquitetura, Universidade Federal do Rio Grande do Sul, 2016. Disponível em: http://www.lume.ufrgs.br/handle/10183/151151. Acesso em: 21 jan. 2019.

TRAMONTANO, Marcelo; PEREIRA JUNIOR, Anibal. Ressignificando o modelo físico: impressão 3D e ensino de projeto de arquitetura. In: CONGRESSO INTERNACIONAL DA SOCIEDADE IBEROAMERICANA DE GRÁFICA DIGITAL, 19., 2015, Florianópolis. Proceedings [...]. São Paulo: Editora Blucher, 2015. p. 350-354.

TRAMONTANO, Marcelo. Quando pesquisa e ensino se conectam: design paramétrico, fabricação digital e projeto de arquitetura. In: CONGRESSO INTERNACIONAL DA SOCIEDADE IBEROAMERICANA DE GRÁFICA DIGITAL, 19., 2015, Florianópolis. Proceedings [...]. São Paulo: Editora Blucher, 2015. p. 544-550. Disponível em: http://pdf.blucher.com.br.s3-sa-east-1.amazonaws.com/designproceedings/sigradi2015/100144.pdf. Acesso em: 21 jan. 2019.

TRAMONTANO, Marcelo; LANDIM, Gabriele; DIGIANDOMENICO, Dyego; SOUZA, Mayara Dias. Jam, ou sobre pesquisa colaborativa em arquitetura e urbanismo. In: CONGRESSO INTERNACIONAL DA SOCIEDADE IBEROAMERICANA DE GRÁFICA DIGITAL, 20., 2016, Buenos Aires. Proceedings [...]. São Paulo: Editora Blucher, 2016. p. 902-906.

\section{${ }^{1}$ lago Longue Martins}

Arquiteto e Urbanista. Graduação. Arquiteto Autônomo. Endereço postal: Avenida Rio Branco, 1540, Praia do Canto, Vitória, ES, Brasil, CEP: 29055-642

\section{${ }^{2}$ Zander Ribeiro Pereira Filho}

Arquiteto e Urbanista. Mestre em Engenharia Ambiental. Professor do Instituto Federal de Educação, Ciência e Tecnologia Fluminense. Endereço postal: Rua Teixeira de Freitas, 266, Parque São Caetano, Campos dos Goytcazes, RJ, Brasil, CEP: 28030-395 